\title{
Effect of Hypoxia on the Expression of a Subset of Proliferation Related Genes in IRE1 Knockdown U87 Glioma Cells
}

\author{
Dariia 0. Tsymbal, Dmytro O. Minchenko, Oksana S. Hnatiuk, \\ Olha Y. Luzina, Oleksandr H. Minchenko*
}

Department of Molecular Biology, Palladin Institute of Biochemistry of the National Academy of Sciences of Ukraine, Kyiv, Ukraine

Email: *ominchenko@yahoo.com

How to cite this paper: Tsymbal, D.O., Minchenko, D.O., Hnatiuk, O.S., Luzina, O.Y. and Minchenko, O.H. (2017) Effect of Hypoxia on the Expression of a Subset of Proliferation Related Genes in IRE1 Knockdown U87 Glioma Cells. Advances in Biological Chemistry, 7, 195-210. https://doi.org/10.4236/abc.2017.76014

Received: November 3, 2017

Accepted: December 27, 2017

Published: December 30, 2017

Copyright (® 2017 by authors and Scientific Research Publishing Inc. This work is licensed under the Creative Commons Attribution International License (CC BY 4.0).

http://creativecommons.org/licenses/by/4.0/

(c) (i) Open Access

\begin{abstract}
We have studied the expression of a subset of genes encoding important tumor growth related factors in U87 glioma cells with IRE1 (inositol requiring enzyme-1) knockdown as well as their hypoxic regulation. It was shown that the expression levels of activating transcription factor 6 (ATF6), clusterin $(C L U)$, adhesion $\mathrm{G}$ protein-coupled receptor E5 ( $A D G R E 5)$, transglutaminase 2, C polypeptide $(T G M 2)$, leukemia inhibitory factor $(L I F)$, phosphoserine aminotransferase 1 (PSAT1), glyoxalase I (GLO1) and tetraspanin 13 (TSPAN13) are significantly down-regulated in glioma cells with the knockdown of IRE1 signaling enzyme. It was also shown that in glioma cells subjected to hypoxia, the expression levels of PSAT1, TSPAN13, EIF $2 A K 3$, and TGM2 genes were up-regulated, whereas the expression of $A T F 6$ gene was down-regulated. At the same time, the expression levels of $L I F, C L U$, and ADGRE5 genes did not change in response to hypoxic treatment. Furthermore, inhibition of IRE1, a key effector of an unfolded protein response pathway, modified the effect of hypoxia on the expression of most studied genes. Present study demonstrates that IRE1 knockdown down-regulated the expression of most studied genes and modified their hypoxic regulation and that these changes possibly contributed to the suppression of glioma growth in cells without IRE1 signaling enzyme function.
\end{abstract}

\section{Keywords}

IRE1 Knockdown, Hypoxia, mRNA Expression, EIF2AK3, ATF6, CLU, PSAT1, TGM2, U87 Glioma Cells

\section{Introduction}

Glioblastoma multiforme is the most morbid type of brain cancer, which is 
highly aggressive tumor with extremely poor prognosis and to date there is no efficient treatment available [1] [2] [3]. Its aggressiveness is due to increased invasion, migration, proliferation, angiogenesis, and a decreased apoptosis [4]. The endoplasmic reticulum stress is an important regulator of glioblastoma multiforme growth [5] [6] [7] [8]. IRE1 signaling is a central and most conservative branch of the unfolded protein response and inhibition of this signaling pathway leads to a suppression of glioma growth through down-regulation of angiogenesis and proliferation processes as a result of metabolic reprogramming of cancer cells [5] [9] [10] [11] [12]. The endoplasmic reticulum stress modifies the expression of numerous regulatory and proliferation related genes, which are responsible for glioma growth [9] [13] [14] [15] [16]. Hypoxia is another important factor to glioma development, which promotes a more aggressive tumor behavior [17] [18]. A better knowledge of tumor responses to hypoxic condition is required to elaborate therapeutically strategies of cell sensibilization, based on the blockade of survival mechanisms [19] [20]. Notably, the effect of hypoxia on the expression levels of a vast number of genes in glioma cells is dependent on IRE1 signaling enzyme function [16] [21] [22].

Numerous genes have already been correlated with glioblastoma multiforme growth. However, their precise role in the development of this type of cancer, as well as the mechanisms by which IRE1 signaling and hypoxia affect their expression are yet to be clarified. Among them are transglutaminase 2 (TGM2), clusterin ( $C L U$ ), adhesion G protein-coupled receptor E5 ( $A D G R E 5)$, leukemia inhibitory factor $(L I F)$, phosphoserine aminotransferase 1 (PSAT1), glyoxalase I (GLO1), and tetraspanin 13 (TSPAN13) as well as eukaryotic translation initiation factor 2 alpha kinase 3 (EIF2AK3) and activating transcription factor 6 (ATF6), which encode important proteins for endoplasmic reticulum stress signaling pathways. A multifunctional protein, TGM2, is overexpressed in several tumors and cancer cell lines and its high expression level correlates with increased level of the long non-coding RNA (LOC107987281) encoded by this gene [23] [24]. Recently, it was shown that the chloride intracellular channel protein 3 (CLIC3) promotes invasive behavior of endothelial cells to drive angiogenesis and increases invasiveness of cancer cells both in vivo and in 3D cell culture models, and this requires active transglutaminase 2 [25]. Moreover, TGM2 was shown to be differentially expressed in U87 glioma cells with IRE1 inhibition as shown by gene expression array [14].

Clusterin is a multifunctional heterodimeric glycoprotein with several isoforms that can play opposite roles in regard to cell survival and apoptosis. It is overexpressed in various types of tumors and its overexpression is believed to promote cancer progression [26] [27] [28] [29]. ADGRE5 (CD97 antigen) mediates cell-cell interactions, which is involved in angiogenesis and cell migration and is also overexpressed in many cancers [30]. The expression of ADGRE5 gene may play a role in the progression of several types of cancer [31]. Leukemia inhibitory factor is a multifunctional highly glycosylated protein, which downregulates tumor suppressor p53 protein level and function in human colorectal cancer cells 
[32] [33]. LIF is frequently overexpressed in many types of human tumors and promotes the progression and metastasis of tumors [34]. It induces the expression of microRNA-21, which in turn mediates the promoting effect of LIF on epithelial-mesenchymal transition. Furthermore, blocking miR-21 function greatly abolished the promoting effect of $L I F$ on epithelial-mesenchymal transition and the migration ability of cancer cells [34].

Phosphoserine aminotransferase PSAT1 plays an important role in the L-serine biosynthesis and implicated in colon cancer progression and chemoresistance [35]. Its overexpression stimulates cell growth and increases chemoresistance of colon cancer cells [35]. Recently was shown that PSAT1, which is overexpressed in ER-negative breast cancers, is activated by $A T F 4$ and promotes cell cycle progression via up-regulation of the cyclin D1 [36]. It should be noted, that a transcription factor $A T F 4$, which regulated $P S A T 1$ expression, belongs to the PKR-like ER kinase-mediated axis of the endoplasmic reticulum stress pathway [5] [36]. TSPAN13 mediates signal transduction events that play a role in the regulation of cell development, activation, growth and motility. TSPAN13 gene was characterized as potential oncogene in non-small cell lung cancer [37]. This data correlate with high levels of TSPAN13 gene expression in prostate cancer and pediatric glioma [38] [39]. Glyoxalase I, a methylglyoxal degradation enzyme, is implicated in the progression of human malignancies and is up-regulated in tumor tissues with high metabolic rate [40] [41]. At the same time, there is data that the activity of GLO1 in high stage colorectal cancer is lower compared to low stage ones [42]. Furthermore, knockdown of GLO1 in the cancer cells significantly reduced tumor-associated properties such as migration and proliferation, whereas hypoxia caused inhibition of cell growth of all cells except of those over-expressing GLO1 [43]. It is possible that over-expression of GLO1 supports malignant transformation and proliferation of cells in a hypoxic environment.

Overall, there is an experimental evidence, that transglutaminase 2 (TGM2), clusterin ( $C L U$ ), adhesion $\mathrm{G}$ protein-coupled receptor E5 (ADGRE5), leukemia inhibitory factor $(L I F)$, phosphoserine aminotransferase 1 (PSAT1) and tetraspanin 13 ( TSPAN13) either act as oncogene or elicit a cytoprotective function on tumor cells. However, not much is known about their role in glioblastoma development.

Eukaryotic translation initiation factor 2 alpha kinase 3 (EIF2AK3), which also known as PKR-like ER kinase (PERK), is an elF2alpha kinase that inhibits protein translation and is involved in control of cell proliferation and tumorigenesis, in mitochondrial function and apoptosis [44] [45] [46]. Both activating transcription factor 6 and PKR-like ER kinase (PERK) are also important signaling proteins of endoplasmic reticulum stress pathway [5]. ATF6 activates stress responsible gene expressions and regulates cellular senescence, which is known as an anti-tumor barrier [5] [47].

The aim of this study was investigation the effect of IRE1 knockdown as well as hypoxia on the expression of EIF $2 A K 3, A T F 6, C L U, P S A T 1, T G M 2, L I F$, 
TSPAN13, GLO1, and ADGRE5 genes in U87 glioma cells with hopes of elucidating their involvement in the development and progression of glioblastoma.

\section{Materials and Methods}

\subsection{Cell Culture}

In this study we used two sublines of U87 glioma cells, which are growing in high glucose ( $4.5 \mathrm{~g} / \mathrm{l})$ Dulbecco's modified Eagle's minimum essential medium (DMEM; Gibco, Invitrogen, USA) supplemented with glutamine (2 mM), 10\% fetal bovine serum (Equitech-Bio, Inc., USA), streptomycin ( $0.1 \mathrm{mg} / \mathrm{ml}$; Gibco) and penicillin (100 units $/ \mathrm{ml}$; Gibco) at $37^{\circ} \mathrm{C}$ in a $5 \% \mathrm{CO}_{2}$ incubator. One subline was obtained by selection of stable transfected clones with overexpression of vector (pcDNA3.1), which was used for creation of dominant-negative constructs (dnIRE1). This untreated subline of glioma cells (control glioma cells) was used as control 1 in the study of effects of hypoxia on the expression level of $E I F 2 A K 3$, ATF6, CLU, PSAT1, TGM2, LIF, TSPAN13, GLO1, and ADGRE5 genes. Second subline was obtained by selection of stable transfected clones with overexpression of dnIRE1 and has suppressed both protein kinase and endoribonuclease activities of this bifunctional sensing and signaling enzyme of endoplasmic reticulum stress. The expression level of studied genes in these cells was compared with cells, transfected by vector (control 1). The subline, which overexpress dnIRE1, was also used as control 2 for investigation the effect of hypoxia on the expression level of studied genes in cells with inhibited signaling enzyme IRE1 function. Clones were grown in the presence of $0.4 \mathrm{mg} / \mathrm{ml}$ geneticin (G418). The suppression level of IRE1 both enzymatic activity in glioma cells that overexpress a dominant-negative construct of inositol requiring enzyme-1 was estimated previously [27] [38] by determining the phosphorylation of IRE1 and the expression level of XBP1 alternative splice variant (XBP1s), a key transcription factor in IRE1 signaling, using cells treated by tunicamycin $(0.01 \mathrm{mg} / \mathrm{ml}$ during 2 hrs). Moreover, the proliferation rate of glioma cells with mutated IRE1 is decreased in 2 fold [30]. Thus, the blockade of both kinase and endoribonuclease activity of signaling enzyme IRE1 has significant effect on proliferation rate of glioma cells.

In experiments with hypoxia culture plates with complete DMEM were exposed in special chamber with $3 \%$ oxygen, $92 \%$ nitrogen, and $5 \%$ carbon dioxide for 16 hrs.

\subsection{RNA Isolation}

Total RNA was extracted from glioma cells using Trisol reagent (Invitrogen, USA) according to manufacturer's protocol. The RNA pellets were washed with $75 \%$ ethanol and dissolved in nuclease-free water. For additional purification RNA samples were re-precipitated with $95 \%$ ethanol and re-dissolved again in nuclease-free water. RNA concentration and spectral characteristics were measured using NanoDrop Spectrophotometer. 


\subsection{Reverse Transcription and Quantitative PCR Analysis}

Thermo Scientific Verso cDNA Synthesis Kit (Germany) were used for cDNA synthesis according to manufacturer's protocols. The expression level of $E I F 2 A K 3$, ATF6, CLU, PSAT1, TGM2, LIF, TSPAN13, ADGRE5, and ACTB mRNA were measured in glioma cell line U87 and its subline (clone 1C5) by real-time quantitative polymerase chain reaction using "QuantStudio 5 Real-Time PCR System" (Applied Biosystems) and RotorGene RG-3000" qPCR (Corbett Research, Germany) and Absolute qPCR SYBRGreen Mix (Thermo Fisher Scientific, ABgene House, Epsom, Surrey, UK). Polymerase chain reaction was performed in triplicate. For analysis of RNA expression four different RNA samples for each experimental group as well as pairs of the specific primers (Table 1), which were received from "Sigma-Aldrich" (St. Louis, MO, USA), were used.

The expression of beta-actin mRNA was used as control of analyzed RNA quantity. The primers were received from "Sigma-Aldrich" (St. Louis, MO, USA). The quality of amplification products was analyzed by melting curves and by electrophoresis using $2 \%$ agarose gel. An analysis of quantitative PCR was performed using special computer program "Differential Expression Calculator". The values of EIF $2 A K 3, A T F 6, C L U, P S A T 1, T G M 2, L I F, T S P A N 13$, and ADGRE5 mRNA expressions were normalized to the expression of beta-actin mRNA and represented as percent of control $1(100 \%)$.

\subsection{Western Blot Analysis}

The cytosol and nuclear extract fractions from control glioma cells and cells with IRE1 signaling enzyme knockdown were received as described previously [48]. The levels of PSAT1, ATF6, and LIF proteins were measured in cytosol fraction of U87 glioma cells by Western blot analysis using anti-PSAT1 mouse polyclonal antibody (Abnova), anti-ATF6 $\alpha$ mouse monoclonal antibody (Santa Cruz Biotechnology), and anti-LIF rabbit polyclonal antibody (Abcam). Rabbit polyclonalanti-HIF-1 $\alpha$ antibody (Novus Biologicals) was used for detection of HIF- $1 \alpha$ protein level in nuclear extract by Western blot analysis as described previously [49]. The anti-ACTB ( $\beta$-actin) and anti-lamin B1 antibody (Santa Cruz Biotechnology) were used for detection of $\beta$-actin and lamin B1 protein levels.

\subsection{Statistical Analysis}

All values are expressed as mean \pm SEM from triplicate measurements performed in 4 independent experiments. Statistical analysis was performed according to Student's $t$-test using Excel program as described previously [50].

\section{Results}

We have studied the effect of hypoxia on the expression of genes encoding EIF2AK3, ATF6, PSAT1, CLU, TGM2, ADGRE5, TSPAN13, LIF, and GLO1 proteins in U87 glioma cells in relation to inhibition of IRE1 signaling enzyme, 
Table 1. Characteristics of the primers used for quantitative real-time polymerase chain reaction.

\begin{tabular}{|c|c|c|c|c|}
\hline Gene symbol & Gene name & Primer's sequence & $\begin{array}{l}\text { Nucleotide numbers } \\
\text { in sequence }\end{array}$ & $\begin{array}{c}\text { GenBank accession } \\
\text { number }\end{array}$ \\
\hline$E I F 2 A K 3$ & $\begin{array}{l}\text { Eukaryotic translation intiation factor } 2 \\
\text { alpha kinase 3; PKR-like ER kinase (PERK) }\end{array}$ & $\begin{array}{l}\text { F: } 5 \text { '-tctgttcagctctgggttgt } \\
\text { R: } 5 \text { '-ccgaagttcaaagtggccaa }\end{array}$ & $\begin{array}{c}946-965 \\
1103-1084\end{array}$ & NM_004836 \\
\hline$A T F 6$ & Activating transcription factor 6 & $\begin{array}{l}\text { F: 5'-tgaacttcgaggatgggttc } \\
\text { R: } 5^{\prime} \text {-tcactccctgagttcctgct }\end{array}$ & $\begin{array}{l}350-369 \\
604-585\end{array}$ & NM_007348 \\
\hline$P S A T 1$ & Phosphoserine aminotransferase 1 & $\begin{array}{l}\text { F: 5'-agaatcttgtgcgggaattg } \\
\text { R: } 5 \text { '-cccaagtttagggtgaacga }\end{array}$ & $\begin{array}{l}238-257 \\
455-436\end{array}$ & NM_021154 \\
\hline$C L U$ & Clusterin; apolipoprotein J (ApoJ) & $\begin{array}{l}\text { F: } 5^{\prime} \text {-acatttggtgcccagaagtc } \\
\text { R: } 5^{\prime} \text {-ctgtggtccagggaaaggta }\end{array}$ & $\begin{array}{l}2199-2218 \\
2388-2369\end{array}$ & NM_001831 \\
\hline$T G M 2$ & Transglutaminase 2 , C polypeptide & $\begin{array}{l}\text { F: 5'-ctaccagggatccagctttg } \\
\text { R: } 5^{\prime} \text {-ctgcccaaaattccaaggta }\end{array}$ & $\begin{array}{l}472-491 \\
652-633\end{array}$ & NM_004613 \\
\hline LIF & Leukemia inhibitory factor & $\begin{array}{l}\text { F: } 5^{\prime} \text {-ccctggtccctactcaacaa } \\
\text { R: } 5^{\prime} \text {-ctggaccctgacaccctaaa }\end{array}$ & $\begin{array}{l}1850-1869 \\
2083-2064\end{array}$ & NM_002309 \\
\hline TSPAN13 & Tetraspanin 13; tetraspan NET-6 & $\begin{array}{l}\text { F: } 5^{\prime} \text {-gcaaccacaggttccaagat } \\
\text { R: } 5^{\prime} \text {-ctcggagactggaaatcagc }\end{array}$ & $\begin{array}{l}225-244 \\
375-356\end{array}$ & NM_014399 \\
\hline$A D G R E 5$ & $\begin{array}{l}\text { Adhesion G protein-coupled receptor E5; } \\
\qquad \text { CD97 antigen }\end{array}$ & $\begin{array}{l}\text { F: 5'-cctcagaactcctcgtgtgt } \\
\text { R: 5'-tgttccagcagtccgagaat }\end{array}$ & $\begin{array}{l}471-490 \\
633-614\end{array}$ & NM_001784 \\
\hline GLO1 & Glyoxalase 1 & $\begin{array}{l}\text { F: 5'-gcgtagtgtgggtgactcct } \\
\text { R: 5'-tcactcgtagcatggtctgc }\end{array}$ & $\begin{array}{c}61-80 \\
240-221\end{array}$ & NM_006708 \\
\hline$A C T B$ & Beta-actin & $\begin{array}{l}\text { F: 5'-gacttcgagcaagagatgg } \\
\text { R: } 5^{\prime} \text {-gcactgtgttggcgtacag }\end{array}$ & $\begin{array}{l}747-766 \\
980-961\end{array}$ & NM_001101 \\
\hline
\end{tabular}

which represents a major signaling pathway of the unfolded protein response. It was shown that the knockdown of IRE1 significantly down-regulates the expression of all studied genes in gene specific manner except EIF $2 A K 3$ gene (Figure 1). For instance, strong down-regulation was shown for $T G M 2$, LIF, GLO1, TSPAN13, and ADGRE5 genes, which expressions have also been associated with tumorigenesis and the progression of various malignancies [24] [30] [32] [37].

We have also studied effect of hypoxia on the expression of EIF $A K 3, A T F 6$, PSAT1, TSPAN13, TGM2, CLU, ADGRE5, LIF, and GLO1 genes in control U87 glioma cells and cells with IRE1 knockdown. As shown in Figure 2(a), in control glioma cells (transfected by empty vector) hypoxia significantly down-regulates the expression of $A T F 6$ gene $(-37 \%)$ but in cells with IRE1 knockdown the level of this gene expression is significantly increased upon hypoxic conditions (+55\%; Figure 2(a)). Thus, inhibition of IRE1 signaling reverses direction of the changes in hypoxic regulation of $A T F 6$ gene.

Next, we have shown that hypoxia significantly up-regulates the expression level of EIF $2 A K 3$ mRNA in control glioma cells $(+41 \%)$, but in cells without functional activity of IRE1 signaling enzyme effect of hypoxia is much smaller (+15\%; Figure 2(b)).

As shown in Figure 2(c) and Figure 2(d), hypoxia up-regulates the expression of genes for TGM2 and TSPAM13 ( $+52 \%$ and $+26 \%$, correspondingly) in U87 glioma cells transfected by empty vector, but inhibition of IRE1 signaling 


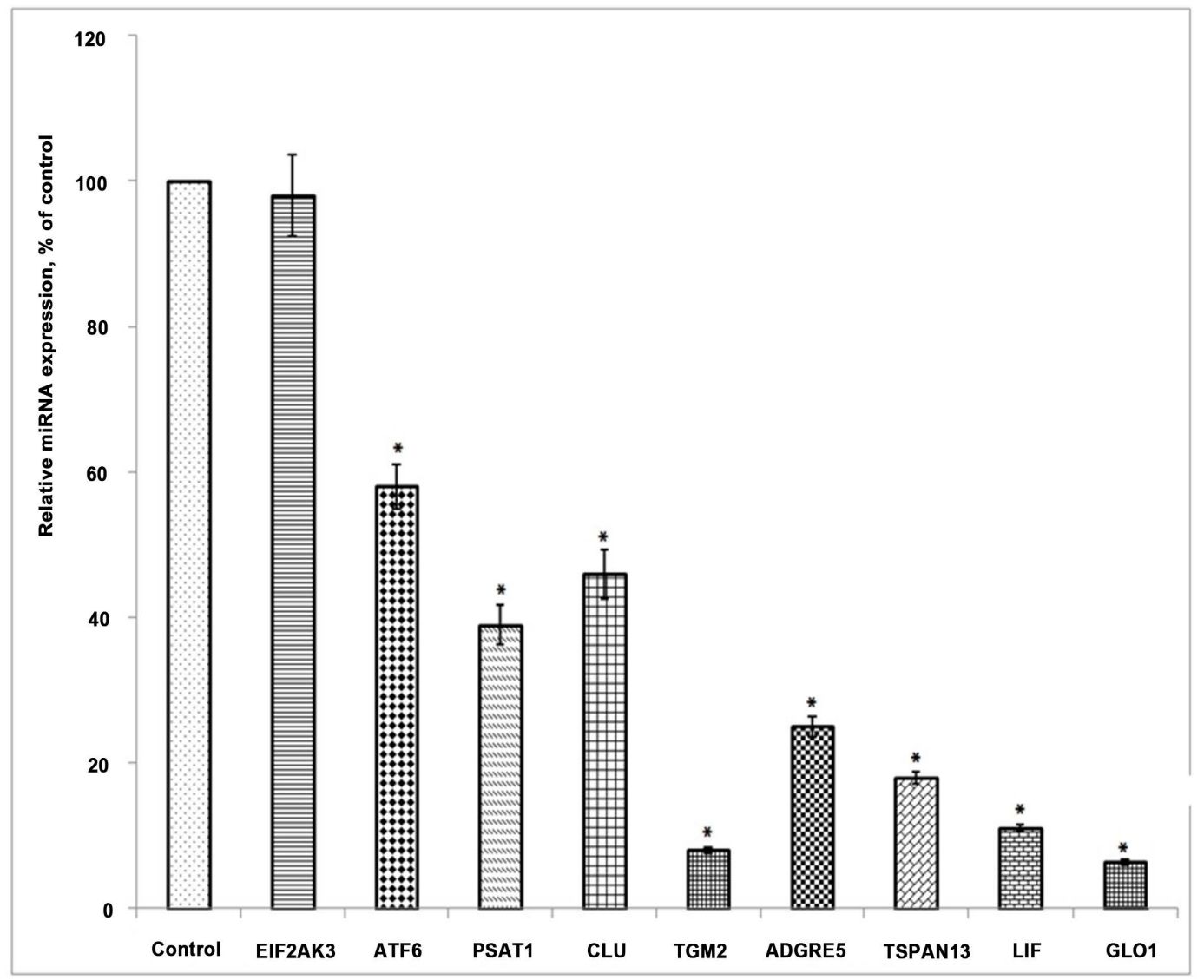

Figure 1. Effect of IRE1 inhibition on the expression level of EIF2AK3,ATF6, PSAT1, CLU, TGM2, $A D G R E 5, T S P A N 13, L I F$, and GLO1 genes in U87 glioma cells. Values of these mRNA expressions were normalized to beta-actin mRNA level and represented as percent for control (cells transfected be empty vector, $100 \%) ; \boldsymbol{n}=4$.

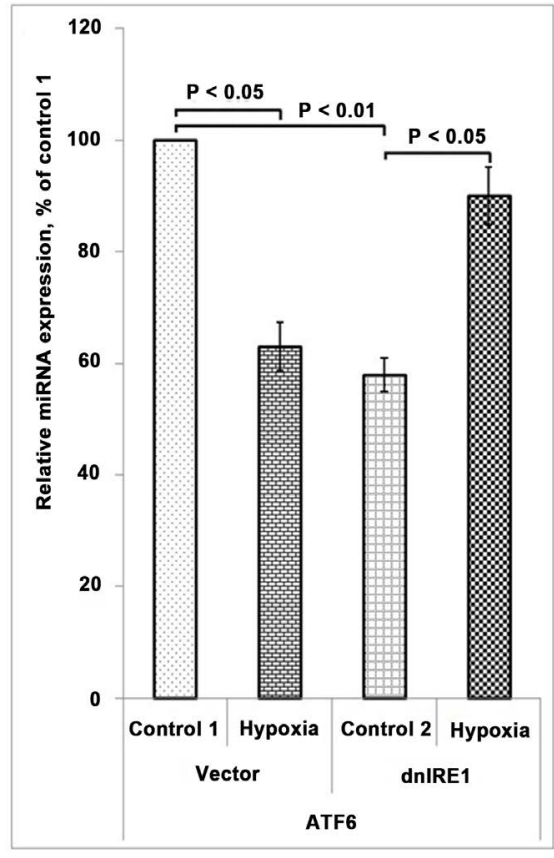

(a)

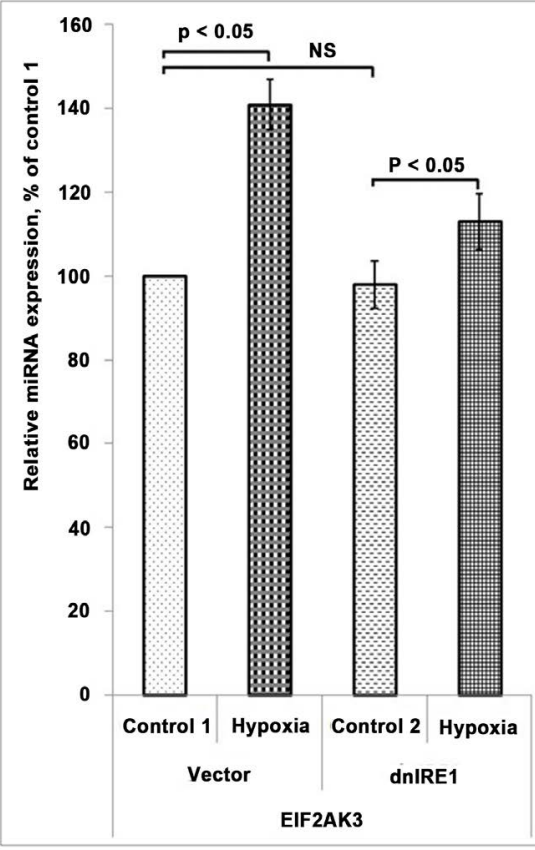

(b)

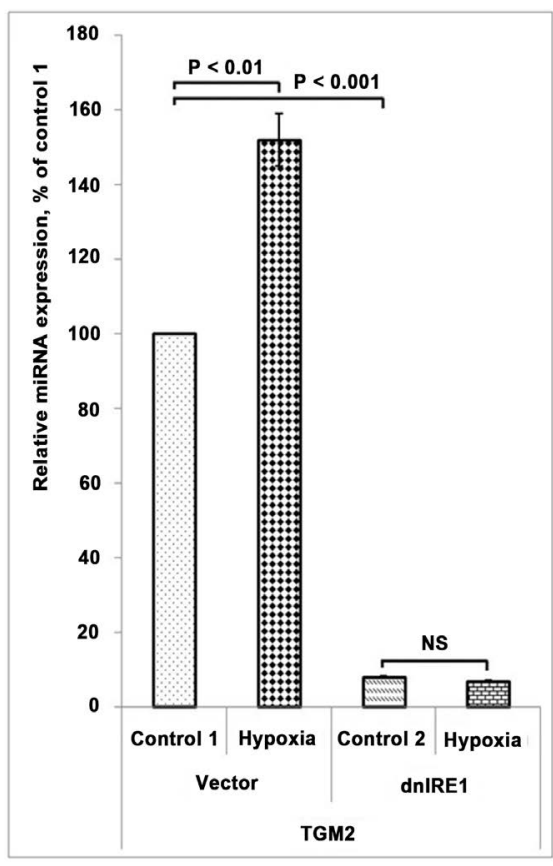

(c) 


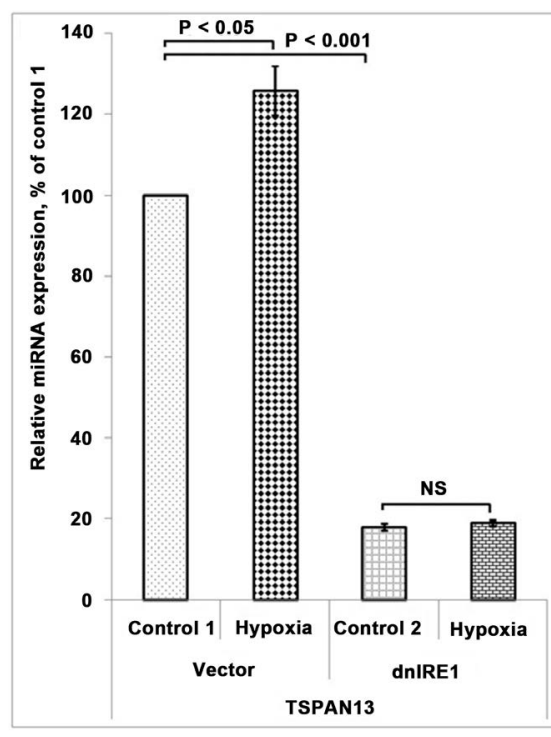

(d)

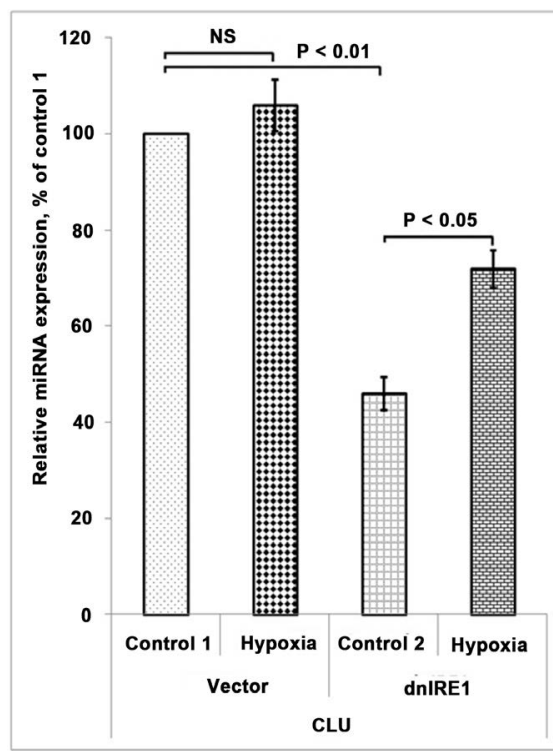

(g)

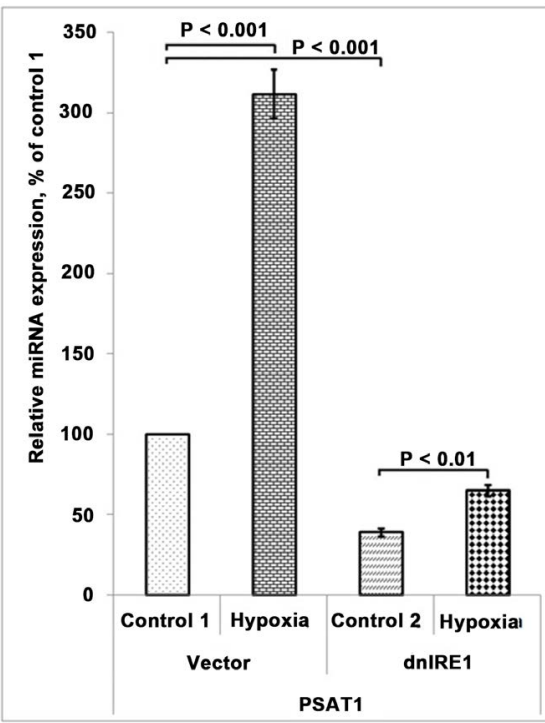

(e)

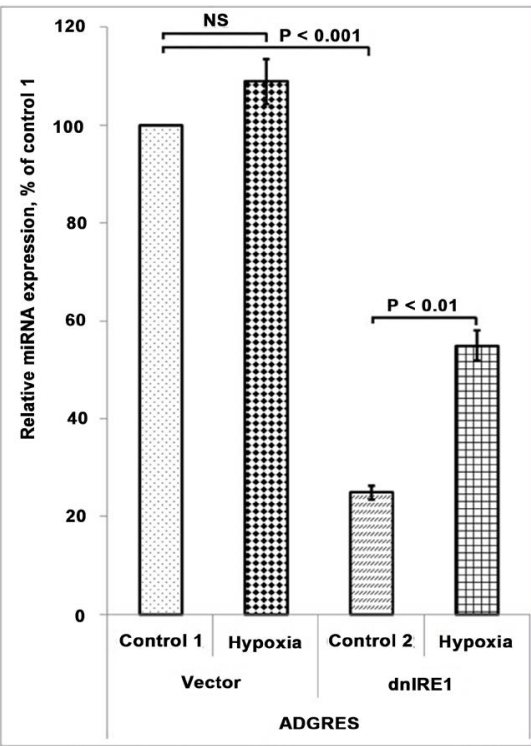

(h)

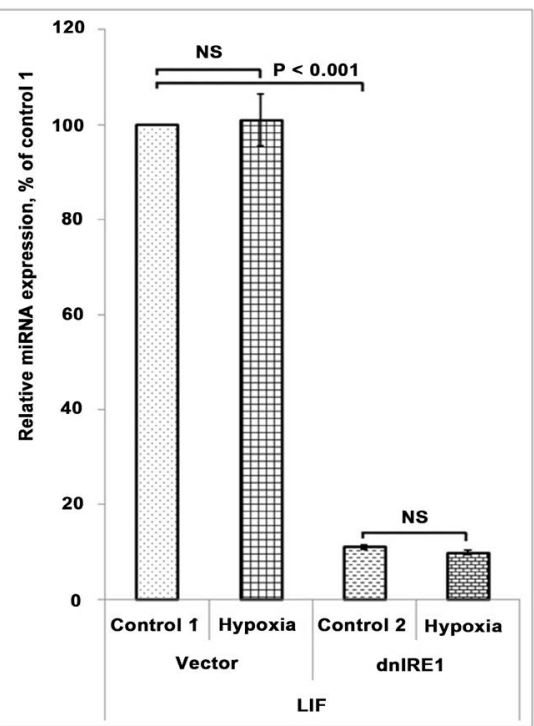

(f)

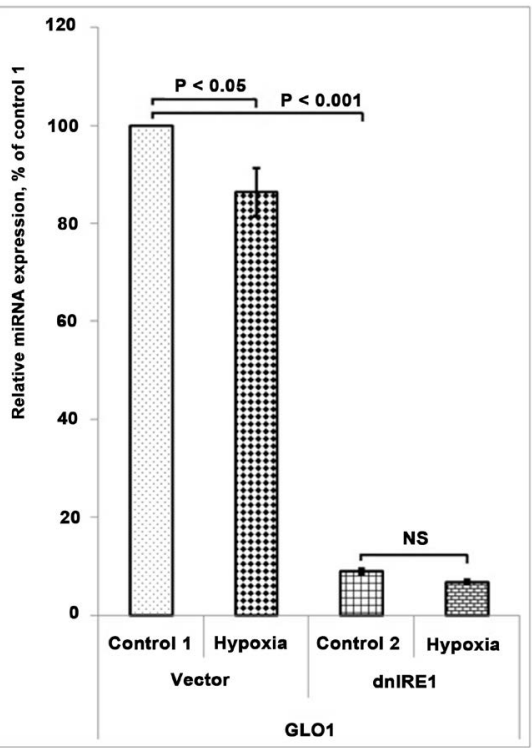

(i)

Figure 2. Effect of hypoxia on the expression levels of: (a) ATF6 (activating transcription factor 6), (b) EIF2AK3 (eukaryotic translation initiation factor 2 alpha kinase 3), (c) TGM2 (transglutaminase 2, C polypeptide), (d) TSPAN13 (tetraspanin 13), (e) PSAT1 (phosphoserine aminotransferase 1), (f) LIF (leukemia inhibitory factor), (g) CLU (clusterin), (h) ADGRE5 (adhesion G protein-coupled receptor E5), and (i) GLO1 (glyoxalase I) mRNAs in control U87 glioma cells (Vector) and cells with IRE1 knockdown (dnIRE1). Values of these mRNA expressions were normalized to beta-actin mRNA level and represented as percent for control $1(100 \%) ; \boldsymbol{n}=4$.

enzyme function by dnIRE1 eliminates effect of hypoxia on these gene expressions.

As shown in Figure 2(e), hypoxia strongly up-regulates the expression of phosphoserine aminotransferase 1 gene in control glioma cells $(+212 \%)$, but in IRE1 knockdown cells effect of hypoxia on the expression of this gene is significantly reduced (+66\%). At the same time, the expression of leukemia inhibitory factor is completely resistant to hypoxic condition in both control and IRE1 
knockdown glioma cells (Figure 2(f)). Next we studied the expression of $C L U$ and ADGRE5 genes in both control and IRE1 knockdown glioma cells. As shown in Figure 2(g), the expression of $C L U$ gene is resistant to hypoxic condition in control glioma cells, but inhibition of IRE1 signaling leads to significant up-regulation of this gene expression upon hypoxia (+56\%). Similar results were received with $A D G R E 5$ gene, which expression was resistant to hypoxia in glioma cells transfected by vector, but inhibition of IRE1 introduced the sensitivity of adhesion G protein-coupled receptor E5 gene to low oxygen condition: treatment of dnIRE1 transfected glioma cells with hypoxia strongly increased the expression level of this mRNA (+120\%; Figure 2(h)). Exposure of both control and IRE1 knockdown U87 glioma cells to hypoxic condition leads to a modest down-regulation of $G L O 1$ gene expression: $-14 \%$ and $-16 \%$, correspondingly (Figure 2(i)).

We have also studied the effect of hypoxia on the levels of PSAT1, ATF6, and LIF proteins in cytosol fraction as well as HIF-1alpha protein in nuclear extract fraction of both control and IRE1 knockdown U87 glioma cells. As shown in Figure 3(a), the changes in PSAT1, ATF6, and LIF proteins level in cytosol fraction are similar to that of mRNA expressions. Furthermore, hypoxia up-regulates HIF-1alpha protein level in the nuclear extract fraction both control glioma cells and cells with inhibited IRE1 signaling in similar way; however, IRE1 knockdown significantly suppresses the level of this protein (Figure 3(b)).

Next we aimed to identify the XBP1-responsive motif (XBP1 CCACG-box) in the promoter region of TSPAN13, PSAT1, TGM2, ATF6, LIF, CLU, GLO1, and $A D G R E 5$ genes. As shown in Table 2, the XBP1 CCACG-box was identified previously by Acosta-Alvear et al. [51]. In the promoter region of both PSAT1 and $A T F 6$ genes we identified two CCACG-boxes, but in TGM2 gene, only one (Table 2). Promoter of LIF gene also contains single XBP1-responsive motif. At the same time, in the promoter region of three other genes we could not identify CCACG-box, a possible XBP1-responsive motif (Table 2).

Thus, inhibition of the endoplasmic reticulum stress mediated by IRE1 signaling enzyme leads to down-regulation of the expression level of most studied proliferation related genes, including gene encoding transcription factor ATF6, which represent signaling branch of the endoplasmic reticulum stress. Most of these genes are differentially regulated by hypoxia in gene specific and IRE1 dependent manner preferentially independently from nuclear level of HIF-1alpha protein.

\section{Discussion}

Results of this investigation clearly demonstrate that inhibition of IRE1, a major signaling enzyme of the endoplasmic reticulum stress, down-regulates of the expression level of proliferation related genes such as PSAT1, CLU, TGM2, $A D G R E 5, T S P A N 13, L I F, G L O 1$, and $A T F 6$, being more prominent for TGM2, LIF, TSPAN13, ADGRE5, GLO1, and PSAT1 genes. These genes have a polyfunctional role in the control of tumor growth and their expressions have been 


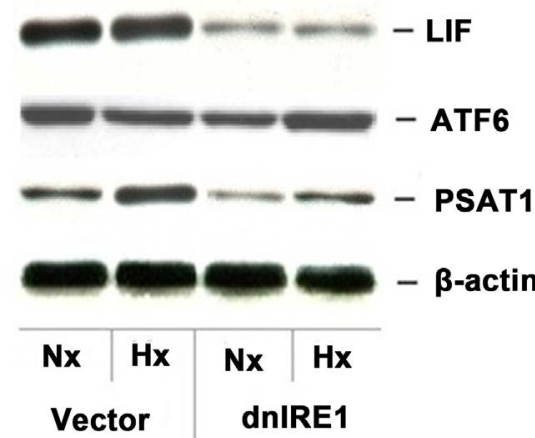

(a)

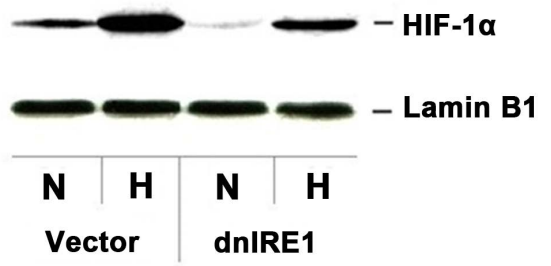

(b)

Figure 3. Effect of hypoxia on the levels of PSAT1, ATF6, and LIF (a) and HIF-1 $\alpha$ (b) proteins in the cytosol and nuclear extract fractions, correspondingly, of control (Vector) and IRE1 knockdown (dnIRE1) U87 glioma cells measured by Western blot analysis. The ACTB ( $\beta$-actin) and lamin B1 proteins were used as control of loaded protein quantity of cytosol and nuclear extract fractions, correspondingly.

Table 2. Matches for XBP1 CCACG-box (XBP1-responsive motif) in the promoter region of TSPAN13, PSAT1, TGM2, ATF6, LIF, CLU, GLO1, and ADGRE5 genes.

\begin{tabular}{cccc}
\hline Gene symbol & $\begin{array}{c}\text { Position relative to the } \\
\text { transcription start site }\end{array}$ & Sequence match & $\begin{array}{c}\text { References/Web site } \\
\text { of promoter sequence }\end{array}$ \\
\hline TSPAN13 & -344 to -340 & gCCACGtc & {$[51]$} \\
PSAT1 & -555 to -551 & tCCACGct & 1 \\
PSAT1 & -630 to -626 & cCCACGtg & 1 \\
TGM2 & -516 to -512 & aCCACGta & 2 \\
ATF6 & -331 to -327 & tCCACGtg & 3 \\
ATF6 & -879 to -875 & gCCACGct & 3 \\
LIF & -423 to -419 & tCCACGcc & 4 \\
CLU & & Not identified & 5 \\
GLO1 & & Not identified & 6 \\
$A D G R E 5$ & & Not identified & NC_000019 \\
\hline
\end{tabular}

1) http://switchdb.switchgeargenomics.com/productinfo/id_713115/;

2) http://switchdb.switchgeargenomics.com/productinfo/id_722826/;

3) http://switchdb.switchgeargenomics.com/productinfo/id_711611/;

4) http://switchdb.switchgeargenomics.com/productinfo/id_719363/;

5) $\underline{\text { http://switchdb.switchgeargenomics.com/productinfo/id_720988/; }}$

6) http://switchdb.switchgeargenomics.com/productinfo/id_718376/.

associated with tumorigenesis and the progression of various malignancies [24] [27] [30] [32] [36] [37], possibly through the endoplasmic reticulum stress. Therefore, our results concerning strong down-regulation of TGM2, TSPAN13, $L I F, A D G R E 5, C L U$, and PSAT1 gene expressions in glioma cells upon inhibition of IRE1 completely agree with functional role of these proteins in tumor cells [24] [27] [30] [32] [36] [37] as well as with suppression of glioma cell proliferation after inhibition of IRE1 signaling enzyme function [7] [22] [25] [26]. Analy- 
sis of promoter region of TSPAN13, TGM2, CLU, ATF6, ADGRE5, LIF, GLO1, and PSAT1 genes showed the presence of possible XBP1 sites in the promoter of 6 genes only: TSPAN13, TGM2, ATF6, LIF, and PSAT1. It is possible that down-regulation of these genes in IRE1 knockdown glioma cells is connected with lack of active XBP1, which is responsible for up-regulation of these genes in glioma cells by the endoplasmic reticulum stress through IRE1 signaling [16]. At the same time, down-regulation of other studied genes in IRE1 knockdown glioma cells could be connected with lack of protein kinase IRE1 or mediated by other mechanisms [9] [15]. Thus, down-regulation of TGM2, CLU, TSPAN13, $L I F, A D G R E 5$, and PSAT1 genes in cells with IRE1 knockdown could possibly contribute to the suppression of glioma growth [14] through inhibition of proliferation, angiogenesis and activation of apoptosis [25] [29] [30] [31] [32] [35] [37] [39]. Moreover, our results have shown that knockdown of IRE1 signaling suppresses the expression of $A T F 6$ gene, which encodes an important transcription factor for the endoplasmic reticulum stress signaling. According to this data down-regulation of the expression of some studied genes in IRE1 knockdown glioma cells, it can be connected with suppression of $A T F 6$ signaling pathway, because transcription factor XBP1 is induced by $A T F 6$ [52].

Results of this investigation clearly demonstrated that hypoxia affects different studied genes in glioma cells in diverse ways: up-regulates or down-regulates in gene specific manner. Moreover, this regulation depends of the IRE1 signaling enzyme function. The expression of most of hypoxia responsible genes is regulated through transcription factor HIF [17]. We have shown that hypoxia strongly up-regulates the level of HIF-1alpha protein both in control glioma cells and cells without the IRE1 signaling enzyme function and that inhibition of IRE1 signaling enzyme function decreases the level of this protein. However, hypoxia changes the expression of various genes in glioma cells in diverse ways [16] [21] [22] [47] and these changes cannot be explained by regulation through transcription factor HIF only. Moreover, hypoxic regulation of the expression of most in this work studied genes is responsive to IRE1-mediated endoplasmic reticulum stress signaling in gene specific manner. Altogether, hypoxic regulation of gene expression is more complex and poly factorial, including regulation through transcription factor HIF or/and through IRE1 signaling pathway. It is interesting to note that hypoxia caused inhibition of cell growth of all cells except tumor cells, which have resistance to toxic effects of hypoxia and used hypoxia for enhanced own cell proliferation. It is possible that this hypoxia resistance is explained by over-expression of GLO1 enzyme, which is implicated in the progression of human malignancies and is up-regulated in tumor tissues with high metabolic rate [40] [41] [43]. In this study, we have shown that inhibition of the IRE1 signaling enzyme leads to strong down-regulation of GLO1 gene expression in U87 glioma cells. Our results agree well with data Hutschenreuther et al. [43] that knockdown of GLO1 in the cancer cells significantly reduced tumor-associated properties such as migration and proliferation, whereas hypoxia 
caused inhibition of cell growth of all cells except of those over-expressing GLO1. Therefore, the changes in expression level of genes encoding PSAT1, CLU, TGM2, ADGRE5, TSPAN13, LIF, and ATF6 proteins possibly reflect reprogramming of glioma cells by IRE1-mediated endoplasmic reticulum stress signaling and correlate with suppression of glioma cell proliferation upon inhibition of the IRE1 signaling enzyme.

\section{Acknowledgements}

This work was supported by a grant from the National Academy of Sciences of Ukraine (Grant No: 0116U001027).

\section{References}

[1] Lieberman, F. (2017) Glioblastoma Update: Molecular Biology, Diagnosis, Treatment, Response Assessment, and Translational Clinical Trials. F1000Research, 6, 1892. https://doi.org/10.12688/f1000research.11493.1

[2] Pearson, J.R.D. and Regad, T. (2017) Targeting Cellular Pathways in Glioblastoma Multiforme. Signal Transduction and Target Therapy, 2, Article ID: 17040. https://doi.org/10.1038/sigtrans.2017.40

[3] Lara-Velazquez, M., Al-Kharboosh, R., Jeanneret, S., Vazquez-Ramos, C., Mahato, D., Tavanaiepour, D., Rahmathulla, G. and Quinones-Hinojosa, A. (2017) Advances in Brain Tumor Surgery for Glioblastoma in Adults. Brain Sciences, 7, E166. https://doi.org/10.3390/brainsci7120166

[4] Valdés-Rives, S.A., Casique-Aguirre, D., Germán-Castelán, L., Velasco-Velázquez, M.A. and González-Arenas, A. (2017) Apoptotic Signaling Pathways in Glioblastoma and Therapeutic Implications. BioMed Research International, 2017, Article ID: 7403747. https://doi.org/10.1155/2017/7403747

[5] Moenner, M., Pluquet, O., Bouchecareilh, M. and Chevet, E. (2007) Integrated Endoplasmic Reticulum Stress Responses in Cancer. Cancer Research, 67, 10631-10634. https://doi.org/10.1158/0008-5472.CAN-07-1705

[6] Galmiche, A., Sauzay, C., Chevet, E. and Pluquet, O. (2017) Role of the Unfolded Protein Response in Tumor Cell Characteristics and Cancer Outcome. Current Opinion in Oncology, 29, 41-47. https://doi.org/10.1097/CCO.0000000000000339

[7] Obacz, J., Avril, T., Le Reste, P.J., Urra, H., Quillien, V., Hetz, C. and Chevet, E. (2017) Endoplasmic Reticulum Proteostasis in Glioblastoma: From Molecular Mechanisms to Therapeutic Perspectives. Science Signaling, 10, eaal2323. https://doi.org/10.1126/scisignal.aal2323

[8] Avril, T., Vauléon, E. and Chevet, E. (2017) Endoplasmic Reticulum Stress Signaling and Chemotherapy Resistance in Solid Cancers. Oncogenesis, 6, e373. https://doi.org/10.1038/oncsis.2017.72

[9] Auf, G., Jabouille, A., Delugin, M., Guérit, S., Pineau, R., North, S., Platonova, N., Maitre, M., Favereaux, A., Vajkoczy, P., Seno, M., Bikfalvi, A., Minchenko, D., Minchenko, O. and Moenner, M. (2013) High Epiregulin Expression in Human U87 Glioma Cells Relies on IRE1alpha and Promotes Autocrine Growth through EGF Receptor. BMC Cancer, 13, 597. https://doi.org/10.1186/1471-2407-13-597

[10] Minchenko, O.H., Tsymbal, D.O. and Minchenko, D.O. (2015) IRE-1alpha Signaling as a Key Target for Suppression of Tumor Growth. Single Cell Biology, 4, 118. https://doi.org/10.4172/2168-9431.1000118 
[11] Lhomond, S., Avril, T., Dejeans, N., Voutetakis, K., Doultsinos, D., McMahon, M., Pineau, R., Obacz, J., Papadodima, O., Jouan, F., Bourien, H., Logotheti, M., Jégou, G., Pallares-Lupon, N., Schmit, K., Le Reste, P.J., Etcheverry, A., Mosser, J., Barroso, K., Vauléon, E., Maurel, M., Samali, A., Patterson, J.B., Pluquet, O., Hetz, C., Quillien, V., Chatziioannou, A. and Chevet, E. (2018) Dual IRE1 RNase Functions Dictate Glioblastoma Development. EMBO Molecular Medicine, 10, e7929. https://doi.org/10.15252/emmm.201707929

[12] Chevet, E., Hetz, C. and Samali, A. (2015) Endoplasmic Reticulum Stress-Activated Cell Reprogramming in Oncogenesis. Cancer Discovery, 5, 586-597.

https://doi.org/10.1158/2159-8290.CD-14-1490

[13] Minchenko, O.H., Kubaichuk, K.I., Minchenko, D.O., Kovalevska, O.V., Kulinich, A.O. and Lypova, N.M. (2014) Molecular Mechanisms of ERN1-Mediated Angiogenesis. International Journal of Physiology and Pathophysiology, 5, 1-22. https://doi.org/10.1615/IntJPhysPathophys.v5.i1.10

[14] Auf, G., Jabouille, A., Guerit, S., Pineau, R., Delugin, M., Bouchecareilh, M., Magnin, N., Favereaux, A., Maitre, M., Gaiser, T., von Deimling, A., Czabanka, M., Vajkoczy, P., Chevet, E., Bikfalvi, A. and Moenner, M. (2010) Inositol-Requiring Enzyme 1alpha Is a Key Regulator of Angiogenesis and Invasion in Malignant Glioma. Proceedings of the National Academy of Sciences of the United States of America, 107, 15553-15558. https://doi.org/10.1073/pnas.0914072107

[15] Minchenko, O.H., Tsymbal, D.O., Moenner, M., Minchenko, D.O., Kovalevska, O.V. and Lypova, N.M. (2015) Inhibition of the Endoribonuclease of ERN1 Signaling Enzyme Affects the Expression of Proliferation-Related Genes in U87 Glioma Cells. Endoplasmic Reticulum Stress in Diseases, 2, 18-29. https://doi.org/10.1515/ersc-2015-0002

[16] Minchenko, D.O., Riabovol, O.O., Ratushna, O.O. and Minchenko, O.H. (2017) Hypoxic Regulation of the Expression of Genes Encoded Estrogen Related Proteins in U87 Glioma Cells: Effect of IRE1 Inhibition. Endocrine Regulations, 51, 8-19.

[17] Kaur, B., Khwaja, F.W., Severson, E.A., Matheny, S.L., Brat, D.J. and Van Meir, E.G. (2005) Hypoxia and the Hypoxia-Inducible-Factor Pathway in Glioma Growth and Angiogenesis. Neuro-Oncology, 7, 134-153. https://doi.org/10.1215/S1152851704001115

[18] Lenihan, C.R. and Taylor, C.T. (2013) The Impact of Hypoxia on Cell Death Pathways. Biochemical Society Transactions, 41, 657-663. https://doi.org/10.1042/BST20120345

[19] Hetz, C., Chevet, E. and Harding, H.P. (2013) Targeting the Unfolded Protein Response in Disease. Nature Reviews Drug Discovery, 12, 703-719. https://doi.org/10.1038/nrd3976

[20] Manié, S.N., Lebeau, J. and Chevet, E. (2014) Cellular Mechanisms of Endoplasmic Reticulum Stress Signaling in Health and Disease. 3. Orchestrating the Unfolded Protein Response in Oncogenesis: An Update. American Journal of Physiology. Cell Physiology, 307, C901-C907. https://doi.org/10.1152/ajpcell.00292.2014

[21] Minchenko, D.O., Kharkova, A.P., Halkin, O.V., Karbovskyi, L.L. and Minchenko, O.H. (2016) Effect of Hypoxia on the Expression of Genes Encoded Insulin-Like Growth Factors and Some Related Proteins in U87 Glioma Cells without IRE1 Function. Endocrine Regulations, 50, 43-54.

[22] Minchenko, O.H., Kryvdiuk, I.V., Minchenko, D.O., Riabovol, O.O. and Halkin, O.V. (2016) Inhibition of IRE1 Signaling Affects Expression of a Subset Genes Encoding for TNF-Related Factors and Receptors and Modifies Their Hypoxic Regulation in U87 Glioma Cells. Endoplasmic Reticulum Stress in Diseases, 3, 1-15. 
https://doi.org/10.1515/ersc-2016-0001

[23] Minotti, L., Baldassari, F., Galasso, M., Volinia, S., Bergamini, C.M. and Bianchi, N. (2018) A Long Non-Coding RNA inside the Type 2 Transglutaminase Gene Tightly Correlates with the Expression of Its Transcriptional Variants. Amino Acids. https://doi.org/10.1007/s00726-017-2528-9

[24] Yamaguchi, H., Kuroda, K., Sugitani, M., Takayama, T., Hasegawa, K. and Esumi, M. (2017) Transglutaminase 2 Is Upregulated in Primary Hepatocellular Carcinoma with Early Recurrence as Determined by Proteomic Profiles. International Journal of Oncology, 50, 1749-1759. https://doi.org/10.3892/ijo.2017.3917

[25] Hernandez-Fernaud, J.R., Ruengeler, E., Casazza, A., Neilson, L.J., Pulleine, E., Santi, A., Ismail, S., Lilla, S., Dhayade, S., MacPherson, I.R., McNeish, I., Ennis, D., Ali, H., Kugeratski, F.G., Al Khamici, H., van den Biggelaar, M., van den Berghe, P.V., Cloix, C., McDonald, L., Millan, D., Hoyle, A., Kuchnio, A., Carmeliet, P., Valenzuela, S.M., Blyth, K., Yin, H., Mazzone, M., Norman, J.C. and Zanivan, S. (2017) Secreted CLIC3 Drives Cancer Progression through Its Glutathione-Dependent Oxidoreductase Activity. Nature Communications, 8, Article No. 14206.

https://doi.org/10.1038/ncomms14206

[26] Mustafi, S., Sant, D.W., Liu, Z.J. and Wang, G. (2017) Ascorbate Induces Apoptosis in Melanoma Cells by Suppressing Clusterin Expression. Scientific Reports, 7, Article No. 3671. https://doi.org/10.1038/s41598-017-03893-5

[27] Tellez, T., Garcia-Aranda, M. and Redondo, M. (2016) The Role of Clusterin in Carcinogenesis and Its Potential Utility as Therapeutic Target. Current Medicinal Chemistry, 23, 4297-4308. https://doi.org/10.2174/0929867323666161024150540

[28] Yoo, M.W., Park, J., Han, H.S., Yun, Y.M., Kang, J.W., Choi, D.Y., Lee, J.W., Jung, J.H., Lee, K.Y. and Kim, K.P. (2017) Discovery of Gastric Cancer Specific Biomarkers by the Application of Serum Proteomics. Proteomics, 17, Article ID: 1600332. https://doi.org/10.1002/pmic.201600332

[29] Lee, J.Y., Kim, H.J., Rho, S.B. and Lee, S.H. (2016) eIF3f Reduces Tumor Growth by Directly Interrupting Clusterin with Anti-Apoptotic Property in Cancer Cells. Oncotarget, 7, 18541-18557. https://doi.org/10.18632/oncotarget.8105

[30] Aust, G., Zhu, D., Van Meir, E.G. and Xu, L. (2016) Adhesion GPCRs in Tumorigenesis. Handbook of Experimental Pharmacology, 234, 369-396.

https://doi.org/10.1007/978-3-319-41523-9_17

[31] Vogl, U.M., Ohler, L., Rasic, M., Frischer, J.M., Modak, M. and Stockl, J. (2017) Evaluation of Prognostic Immune Signatures in Patients with Breast, Colorectal and Pancreatic Cancer Receiving Chemotherapy. Anticancer Research, 37, 1947-1955. https://doi.org/10.21873/anticanres.11535

[32] Yu, H., Yue, X., Zhao, Y., Li, X., Wu, L., Zhang, C., Liu, Z., Lin, K., Xu-Monette, Z.Y., Young, K.H., Liu, J., Shen, Z., Feng, Z. and Hu, W. (2014) LIF Negatively Regulates Tumour-Suppressor p53 through Stat3/ID1/MDM2 in Colorectal Cancers. Nature Communications, 5, Article No. 5218. https://doi.org/10.1038/ncomms6218

[33] Liu, J., Yu, H. and Hu, W. (2015) LIF Is a New p53 Negative Regulator. Journal of Nature and Science, 1, e131.

[34] Yue, X., Zhao, Y., Zhang, C., Li, J., Liu, Z., Liu, J. and Hu, W. (2016) Leukemia Inhibitory Factor Promotes EMT through STAT3-Dependent miR-21 Induction. Oncotarget, 7, 3777-3790. https://doi.org/10.18632/oncotarget.6756

[35] Vié, N., Copois, V., Bascoul-Mollevi, C., Denis, V., Bec, N., Robert, B., Fraslon, C., Conseiller, E., Molina, F., Larroque, C., Martineau, P., Del Rio, M. and Gongora, C. (2008) Overexpression of Phosphoserine Aminotransferase PSAT1 Stimulates Cell 
Growth and Increases Chemoresistance of Colon Cancer Cells. Molecular Cancer, 7, 14. https://doi.org/10.1186/1476-4598-7-14

[36] Gao, S., Ge, A., Xu, S., You, Z., Ning, S., Zhao, Y. and Pang, D. (2017) PSAT1 Is Regulated by ATF4 and Enhances Cell Proliferation via the GSK3 $\beta$ / $\beta$-Catenin/Cyclin D1 Signaling Pathway in ER-Negative Breast Cancer. Journal of Experimental \& Clinical Cancer Research, 36, 179. https://doi.org/10.1186/s13046-017-0648-4

[37] Al Zeyadi, M., Dimova, I., Ranchich, V., Rukova, B., Nesheva, D., Hamude, Z., Georgiev, S., Petrov, D. and Toncheva, D. (2015) Whole Genome Microarray Analysis in Non-Small Cell Lung Cancer. Biotechnology, Biotechnological Equipment, 29, 111-118. https://doi.org/10.1080/13102818.2014.989179

[38] Minchenko, D.O., Novik, Y.E., Maslak, H.S., Tiazhka, O.V. and Minchenko, O.H. (2015) Expression of PFKFB, HK2, NAMPT, TSPAN13 and HSPB8 Genes in Pediatric Glioma. Likarska Sprava, 7-8, 43-48.

[39] Arencibia, J.M., Martín, S., Pérez-Rodríguez, F.J. and Bonnin, A. (2009) Gene Expression Profiling Reveals Overexpression of TSPAN13 in Prostate Cancer. International Journal of Oncology, 34, 457-463.

[40] Guo, Y., Zhang, Y., Yang, X., Lu, P., Yan, X., Xiao, F., Zhou, H., Wen, C., Shi, M., Lu, J. and Meng, Q.H. (2016) Effects of Methylglyoxal and Glyoxalase I Inhibition on Breast Cancer Cells Proliferation, Invasion, and Apoptosis through Modulation of MAPKs, MMP9, and Bcl-2. Cancer Biology \& Therapy, 17, 169-180. https://doi.org/10.1080/15384047.2015.1121346

[41] Geng, X., Ma, J., Zhang, F. and Xu, C. (2014) Glyoxalase I in Tumor Cell Proliferation and Survival and as a Potential Target for Anticancer Therapy. Oncology Research and Treatment, 37, 570-574. https://doi.org/10.1159/000367800

[42] Chiavarina, B., Nokin, M.J., Bellier, J., Durieux, F., Bletard, N., Sherer, F., Lovinfosse, P., Peulen, O., Verset, L., Dehon, R., Demetter, P., Turtoi, A., Uchida, K., Goldman, S., Hustinx, R., Delvenne, P., Castronovo, V. and Bellahcène, A. (2017) Methylglyoxal-Mediated Stress Correlates with High Metabolic Activity and Promotes Tumor Growth in Colorectal Cancer. International Journal of Molecular Sciences, 18, 213. https://doi.org/10.3390/ijms18010213

[43] Hutschenreuther, A., Bigl, M., Hemdan, N.Y., Debebe, T., Gaunitz, F. and Birkenmeier, G. (2016) Modulation of GLO1 Expression Affects Malignant Properties of Cells. International Journal of Molecular Sciences, 17, 2133. https://doi.org/10.3390/ijms17122133

[44] Zhang, M., Liu, X., Wang, Q., Ru, Y., Xiong, X., Wu, K., Yao, L. and Li, X. (2017) NDRG2 Acts as a PERK Co-Factor to Facilitate PERK Branch and ERS-Induced Cell Death. FEBS Letters, 591, 3670-3681. https://doi.org/10.1002/1873-3468.12861

[45] Wang, S.Q., Wang, X., Zheng, K., Liu, K.S., Wang, S.X. and Xie, C.H. (2017) Simultaneous Targeting PI3K and PERK Pathways Promotes Cell Death and Improves the Clinical Prognosis in Esophageal Squamous Carcinoma. Biochemical and Biophysical Research Communications, 493, 534-541. https://doi.org/10.1016/j.bbrc.2017.08.156

[46] Márton, M., Kurucz, A., Lizák, B., Margittai, É., Bánhegyi, G. and Kapuy, O. (2017) A Systems Biological View of Life-and-Death Decision with Respect to Endoplasmic Reticulum Stress-The Role of PERK Pathway. International Journal of Molecular Sciences, 18, 58. https://doi.org/10.3390/ijms18010058

[47] Druelle, C., Drullion, C., Deslé, J., Martin, N., Saas, L., Cormenier, J., Malaquin, N., Huot, L., Slomianny, C., Bouali, F., Vercamer, C., Hot, D., Pourtier, A., Chevet, E., Abbadie, C. and Pluquet, O. (2016) ATF6a Regulates Morphological Changes Asso- 
ciated with Senescence in Human Fibroblasts. Oncotarget, 7, 67699-67715. https://doi.org/10.18632/oncotarget.11505

[48] Armstead, V.E., Minchenko, A.G., Campbell, B. and Lefer, A.M. (1997) P-Selectin Is Up-Regulated in Vital Organs during Murine Traumatic Shock. FASEB Journal, 11, 1271-1279. https://doi.org/10.1096/fasebj.11.14.9409546

[49] Minchenko, O., Opentanova, I., Minchenko, D., Ogura, T. and Esumi, H. (2004) Hypoxia Induces Transcription of 6-phosphofructo-2-kinase/fructose-2,6 isphosphatase 4 Gene via Hypoxia-Inducible Factor-1alpha Activation. FEBS Letterts, 576, 14-20. https://doi.org/10.1016/j.febslet.2004.08.053

[50] Bochkov, V.N., Philippova, M., Oskolkova, O., Kadl, A., Furnkranz, A., Karabeg, E., Breuss, J., Minchenko, O.H., Mechtcheriakova, D., Hohensinner, P., Rychli, K., Wojta, J., Resink, T., Binder, B.R. and Leitinger, N. (2006) Oxidized Phospholipids Stimulate Angiogenesis via Induction of VEGF, IL-8, COX-2 and ADAMTS-1 Metalloprotease, Implicating a Novel Role for Lipid Oxidation in Progression and Destabilization of Atherosclerotic Lesions. Circulation Research, 99, 900-908.

https://doi.org/10.1161/01.RES.0000245485.04489.ee

[51] Acosta-Alvear, D., Zhou, Y., Blais, A., Tsikitis, M., Lents, N.H., Arias, C., Lennon, C.J., Kluger, Y. and Dynlacht, B.D. (2007) XBP1 Controls Diverse Cell Type and Condition-Specific Transcriptional Regulatory Networks. Molecular Cell, 27, 53-66. https://doi.org/10.1016/j.molcel.2007.06.011

[52] Yoshida, H., Matsui, T., Yamamoto, A., Okada, T. and Mori, K. (2001) XBP1 mRNA Is Induced by ATF6 and Spliced by IRE1 in Response to ER Stress to Produce a Highly Active Transcription Factor. Cell, 107, 881-891.

https://doi.org/10.1016/S0092-8674(01)00611-0 